\title{
La vulnerabilidad de los adolescentes ante las sectas. Propuestas educativas
}

\author{
Ma ÁNGELES HERNÁNDEZ PRADOS \\ DAVID IBÁÑEZ BORDALLO* \\ Universidad de Murcia - España \\ Recibido el 28-11-2015; primera evaluación el 04-03-2016; segunda evaluación \\ el 08-05-2016; tercera evaluación el 14-07-2016; aceptado el 21-07-2016
}

\section{RESUMEN}

La fractura de la unicidad del discurso imperante en la modernidad nos ha sumergido en la desesperanza de la relatividad de las voces de la posmodernidad. Asistimos, según García (2008) a una era nueva caracterizada por la implantación de un supermercado espiritual y por el cóctel de las religiones. La sensibilización de la ciudadanía por el cultivo de la interioridad junto a la crisis de las instituciones de acogida agudiza la vulnerabilidad de las personas ante las influencias de ideologías sectarias. Tras el análisis de la sociedad como cultivo para las sectas, el discurso se centra en los adolescentes como etapa de mayor vulnerabilidad, así como en reivindicar la respuesta educativa, desde diferentes contextos, para prevenir la captación de los mismos

Palabras clave: adolescentes, creencias, ciudadanía y valores, prevención.

\footnotetext{
* Licenciada en Filosofía y Ciencias de la Educación (Pedagogía), galardonada con el Premio Nacional fin de Carrera. Doctora en Pedagogía (2004). Profesora contratada doctora (2008) acreditada para titular (2015) en el Departamento de Teoría e Historia de la Educación en la Universidad de Murcia. Cuenta con más de 200 aportaciones a eventos científicos, y más de una treintena de artículos en revistas de gran impacto como Revista Española de Pedagogía, Educación XX1, Teoría de la Educación, Procedía, Aula Abierta, Fuentes, Cuadernos de Pedagogía, entre otras. Contacto: mangeles@um.es

${ }^{*}$ Graduado en Educación Primaria con mención en Educación Intercultural, ha participado en el programa Interjom. Máster en Formación de Profesorado en la especialidad de Orientación Educativa y experto universitario en Historia y Filosofía de las Religiones por la Fundación Xavier Zubiri. Actualmente es doctorando en el Programa de Doctorado en Educación de la Escuela Internacional de Doctorado de la Universidad de Murcia. Contacto: d.ibanezbordallo@ um.es
} 


\section{Vulnerability of Teenagers to sects' recruitment}

\section{Abstract}

The uniqueness» fracture of the ruling speech about modernity has plunged us into despair of relativity voices of postmodernism. We assist, according to Garcia (2008), to a new era characterized by the implementation of a spiritual market and a religions cocktail. The increased sensitivity of citizenship by cultivating integrity along with the host institutions crisis exacerbates the vulnerability of people to be influenced of sectarian ideologies. After having analyzed society as a beneficial crop to the sects, the speech focused on adolescence as the most vulnerable stage, claiming that education, from many different contexts, is the most likely response to prevent the sect»s recruitment.

Keywords: adolescents, beliefs, citizenship and values, prevention.

\section{A vulnerabilidade dos adolescentes nas seitas}

\section{Resumo}

A fratura da unicidade do discurso dominante na modernidade mergulhou-nos no desespero da relatividade das vozes do pós-modernismo. Atendemos, de acordo com Garcia (2008) para uma nova era caracterizada pela implementaçáo de um supermercado espiritual, e pelo cocktail das religióes. A sensibilização da cidadania pelo cultivo da interioridade junto com a crise das instituiçóes de acolhimento aumenta a vulnerabilidade das pessoas nas influências das ideologias sectárias. Após a analise da sociedade como cultivo para as seitas, o discurso centra-se nos adolescentes como a fase de mais vulnerabilidade, assim como a reivindicação na resposta educativa, desde diferentes contextos, para prevenir a captaçấo dos mesmos.

Palavras-chave: adolescentes, crenças, cidadania e valores, prevenção. 


\section{INTRODUCCIÓN}

La vulnerabilidad de los adolescentes se ha puesto en evidencia desde distintas perspectivas (social, política, laboral, educativa, e incluso familiar). No cabe duda que la etapa de contingencia e inestabilidad de las instituciones, descrita por autores relevantes como Bauman con su metáfora de las sociedades líquidas (2005) o por Dubet (2006) en el declive de las instituciones, ha contribuido en parte a la conciencialización de dicho estado, enfatizando la necesidad de atender y dar respuesta a las necesidades de este sector poblacional.

Partimos del análisis de la cara más oscura de la sociedad como punto de arranque del desconcierto al que se ven sometidos parte de los adolescentes carentes de referentes de socialización, para posteriormente adentrarnos en la búsqueda que estos realizan de modelos alternativos, viéndose en ocasiones atrapados por sectas. Nos encontramos ante un tema de gran relevancia social, escasamente abordado desde una perspectiva científico-educativa. Por ende, consideramos que ha llegado el momento de exponer, aunque sea desde un ensayo teórico, los factores de la sociedad que han podido contribuir a la proliferación de grupos sectarios y al aumento de sus seguidores, especialmente entre los más jóvenes, con la finalidad de sensibilizar a diversos sectores de la sociedad, entre ellos a la comunidad educativa (familias y docentes). Con ese trabajo esperamos suscitar el debate socioeducativo de la vulnerabilidad de los adolescentes y el poder de captación de las sectas, ya que aquí se expone de forma general y sería conveniente un análisis pormenorizado atendiendo a las peculiaridades de cada país.

\section{LA DESESPERANZA COMO FIN DE LA POSMODERNIDAD}

Es un convenio entre los expertos que nuestras sociedades se encuentren en un convulso y delicado proceso de transformación, insólito en la historia. Un momento que se presenta para muchos como la culminación del cambalache, problemático y febril que con acierto profetizó Discépolo ${ }^{1}$, donde la búsqueda innata de sentido se anuncia como una tarea desconcertante y abrumadora.

Este escenario histórico-social se caracteriza por la deconstrucción de las macroconfiguraciones globales formales y la fracturación del orden moral ortodoxo, dando paso a una heterogeneidad de éticas individuales fluidas y cambiantes que coexisten en un modelo de sociedades complejas o de riesgo

\footnotetext{
1 Enrique Santos Discépolo (Buenos Aires, 27 de marzo de 1901 - Buenos Aires, 23 de diciembre de 1951) fue un compositor, músico, dramaturgo y cineasta argentino.
} 
(Canteras, 2004). Con el caos, la transitoriedad y la inestabilidad propia de la modernidad líquida, los sólidos persisten en el tiempo, mientras que los líquidos se transforman constantemente (Bauman, 2005).

No queremos perdernos en el discurso de los calificativos, tan habitual como necesario, pero con el peligro implícito de quedar atrapados en el mismo, desatendiendo otros asuntos de mayor relevancia. Tal y como expuso Gabilondo (2001) al adentrarnos en el postmodernismo ingresamos en un espacio de calificativos que nos impide hablar de lo que interesa, subrayando que nos encontramos ante otra lectura del alma, la cual deja de ser singular para situarse en el alma plural.

El reconocimiento de la pluralidad rompe con el amurallamiento de la configuración masiva del ser por parte de las instituciones y se acentúan las dificultades de legitimación de unas instituciones, presionarias según la terminología foucaultiana $\mathrm{u}$ opresoras en términos freirianos, creadas para mantener un tipo de formación social que está desapareciendo, y cuya principal función es la de vigilar y castigar para el mantenimiento y perpetuación de una sociedad disciplinaria y/o normativa.

Como consecuencia de la fractura de la tesis durkheimiana derivada de la desinstitucionalización, se evidencia la necesidad de la acogida y reconocimiento del otro, cuya mismidad, marcada por las circunstancias vivenciales, le definen y dan sentido (heteronomía del self). Así pues, frente a la atención narcisista y obsesiva del cuerpo, su salud y sus placeres, se plantea la necesidad de hacernos cargo de las llamadas nuevas enfermedades del alma, porque la pérdida de un verdadero rostro no reclama sustitución, sino atención a lo cercano, inmediato, de todo cuanto tiene color, epidermis y apariencia (Gabilondo, 2001).

Tradicionalmente la familia y la iglesia constituyen las instituciones de acogida primogénitas, ya que nuestro inacabamiento biológico nos convierte en seres sociales necesitados de atención y cuidado, tanto del cuerpo como del alma. Pero estas están viéndose cuestionadas por «una sociedad cada día más agresiva, en la que la solidaridad se ha institucionalizado, pedimos más y más a la familia a la que queremos gratuita y no competitiva. De ahí su éxito, de ahí su fragilidad» (Elzo, 2004, p. 29). Por tanto, hablar de crisis de las instituciones, es hablar de crisis de acogida, es decir, del reconocimiento de los estados de vulnerabilidad que nos caracterizan, aflorando el sentimiento de desamparo, de fragilidad del ser humano, como si de un huérfano se tratase.

Ante la desesperanza de la relatividad de las voces emergentes en la posmodernidad, se despierta cierta sensibilización ciudadana hacia la interioridad, como esencia que permite construir y dotar de sentido la existencia humana, 
pues «sería horrible que sintiésemos la opresión, pero no pudiésemos imaginar un mundo diferente, sońar con él como proyecto y entregarnos a la lucha para su construcción» (Freire, 2001, p. 144). Se trata de fomentar el cultivo del ser frente el tener, bien sea desde la pedagogía de la reflexividad, lo que implica la creación de espacios de pensamiento y consideración de uno mismo, o desde la pedagogía de la alteridad, que lleva implícito no tanto el pensar, como el sentir, actuar y vivir desde la relación con el otro. En ambos casos la construcción de la subjetividad se sitúa como epicentro de la acción educativa y se realiza a partir de la pregunta, pero el punto de partida es diferente, mientras que en la primera la cuestión nace de uno mismo y de la razón, en la segunda, nace del otro y del sentimiento moral.

Esta búsqueda de formas de vida, de existencialismo propias de la orfandad que vivimos ha dado lugar a una nueva era caracterizada, según García (2008) por una red nebulosa de fronteras difusas que se ha alimentado de las más poliformes tradiciones místicas, mágicas y esotéricas, denominada como el supermercado espiritual de la posmodernidad, así como una tendencia a buscar y esperar un cambio de paradigma que revolucione el estado actual de la cultural, el pensamiento y la sociedad, en un intento de buscar la salud espiritual a partir del cocktail mistico existente.

Muchas veces las respuestas a esas cuestiones naturalmente humanas, vinculadas con el sentido de la vida, su propia existencia, la muerte, entre otras; han tomado forma religiosa. Pero las religiones históricas parecen haber quedado desfallecidas tras los acontecimientos que han herido profundamente el alma de occidente durante el siglo XX y su adaptación al nuevo escenario social, ideológico, espiritual y emocional; parece enteco.

En estas circunstancias de incertidumbre se produce una disputa entre política y religión por conquistar el mismo territorio, ganar socios-seguidores, oscilando entre la alianza y la enemistad (Bauman, 2012). Es así como toma fundamento la teoría del mercado religioso propio de la sociedad de competencia, que empujan a las distintas confesiones a adoptar estrategias pastorales propias del marketing: "cada iglesia ${ }^{2}$ desea colocar su producto y alcanzar al mayor número posible de clientes; pero para lograrlo se ve obligada a renunciar a purismos teológicos y acomodarse a los gustos y necesidades del consumidor» (Fierro, 1979, 83).

De esta manera, como explican Fournier y Picard (2004), las organizaciones sectarias «se deslizan hábilmente sobre las preguntas que todo el mundo se hace acerca del sentido de la vida» asegurando que "responden [eficazmente]

\footnotetext{
2 Entiéndase ampliamente, «cada confesión religiosa...».
} 
a la generalización de la duda y la angustia proponiendo soluciones milagrosas» (p. 89). En este sentido, el fenómeno sectario se ofrece como respuesta a una demanda de sentido fruto de una espiritualidad no satisfecha.

En cierta medida, se puede decir que el desgaste de las ideologías seculares, el detrimento de las iglesias tradicionales y la crisis de sentido posmoderna han convertido el mundo, como se apuntaba anteriormente, en un variado supermercado de creencias donde se mezcla lo psicológico, lo pseudoreligioso, lo psicológico con lo dramático (Jiménez Tallón, 1997). Si Dios ha muerto en las sociedades posmodernas, lejos de ser sustituido por un algo mejor, quizás un sistema ético universal, más razonable y humanista (quizás el propio Übermensch nietzscheriano o la propia diosa Razón que adoraban los filósofos ilustrados), se ha completado su vacio con un panteón posmoderno de ofertas espirituales, muchas veces con intereses deshonestos y estrategias perfectamente adaptadas a la forma más despiadada de nuestro modelo de mercado (para el que el ser humano es poco más que un recurso).

La discusión clásica sobre el sentido de las religiones, en el que se cuestiona la veracidad de las respuestas teodiceas o mitológicas a preguntas metafísicas naturales y verdaderas, con la intención más o menos noble de ofrecer sentido, pertenencia o consuelo y establecer cierto control u orden moral y social, queda superada por las sectas. Estos modos nocivos de creencia se han adaptado perfectamente a las peores formas de nuestro pensamiento contemporáneo: el ser humano no es un fin en sí mismo, como diría Kant, sino un simple medio, un mero producto aprovechable del que extraer beneficios (económicos y de poder); exprimiéndolo y esclavizándolo incluso desde sus necesidades más íntimas de sentido y transcendencia. En cierta manera, podríamos decir que las sectas han subyugado a los hijos a los que la muerte de Dios dejó huérfanos.

Estas organizaciones parecen haber encontrado fórmulas eficaces para pescar en este rio revuelto de la espiritualidad contemporánea, encontrando en la desesperanza y la insatisfacción que en muchas ocasiones causa la vida moderna un fructífero nicho de mercado. La forma de pensar y de vivir en las sociedades actuales, donde el desarrollo del ser parece alcanzar su éxito únicamente en su capacidad para producir y consumir, sumado a cierto grado de infantilismo y de escándalo frente al sufrimiento, junto con la nausea (en el lenguaje de Sartre) que parece acompañar a cualquier reflexión posmoderna sobre la existencia, hace de las sectas una salida aparentemente rápida y exitosa. Como bien explica Jiménez Tallón (1997), «cuando las circunstancias vitales son vividas como perturbadoras, el ingreso en una secta u otras vías de escape, como las drogas, el alcohol o incluso el suicidio, son considerados como refugios para huir de la propia angustia vital» (p. 123). La oferta espiritual que 
brindan, superficialmente plausible, atractiva y cargada con promesas de éxito, conforman una solución aparentemente asequible y un lugar de desarrollo; tanto como espacio de protección, arraigo, fuga mundi o de sentido frente a la desesperanza, como para alcanzar un éxito más rápido y efectivo en este mismo sentido consumista. Es aceptado entre los investigadores del fenómeno sectario que los nuevos adeptos son generalmente felices: «una felicidad, muy efímera, que se paga muy cara: con la esclavitud» (Fournier \& Picard, 2004, p. 250).

Así, el ser moderno acostumbrado a satisfacer sus necesidades propias (reales o inspiradas) eligiendo entre la multitud de ofertas del mercado, también encuentra para sus necesidades espirituales o trascendentes un amplio y creciente mercado del alma, que en demasiadas ocasiones está lleno de malas intenciones, sofisticadas técnicas de captación y corrupción, trampas, peligros y celdas con barrotes dorados, en la metáfora de Alapont (2005), que se tornan especialmente atractivos para los más vulnerables. La adolescencia como etapa caracterizada por la ruptura de los lazos primarios en la búsqueda de la construcción de la propia identidad, se encuentra en plena dispersión, resultando una presa fácil para los encantadores de almas, siguiendo el símil de los encantadores de serpientes

\section{VulNerabilidad DE LOS ADOLESCENTES ANTE El PODER DE CAPTACIÓN DE LAS SECTAS}

Se entiende la adolescencia como una etapa de construcción y socialización crítica y compleja para la consolidación del ser, pues constituyen «las primeras disposiciones mentales y comportamentales que van a marcar muy duraderamente a los individuos» (Lahire, 2007, p. 22). Converge además en este tramo vital la conflictividad característica de esta etapa con cierta desarmonía evolutiva fruto del desarrollo intelectual adecuado enfrentado al infantilismo afectivo; generándose así factores que agudizan la vulnerabilidad ante la oferta de experiencias que ofrecen protección, autonomía, madurez y calman la ansiedad como pueden ser las drogas, sectas, bandas juveniles, etc.. Como proponen Biglan, Brennan, Foster y Holder (2004), podría considerarse la adolescencia, por su propia idiosincrasia, como una etapa de agudización del riesgo en múltiples ámbitos.

Se trata de una etapa caracterizada por el relativismo y el minimalismo con el que asumen los riesgos, y la desatención a los consejos provenientes de modelos adultos del entorno más cercano. Generalmente la etapa de la adolescencia se caracteriza por el alejamiento del contexto familiar y la 
búsqueda de nuevos grupos de referencia, lo que les convierte en un sector de riesgo ante las sectas. Pero la realidad es mucho más compleja, la verdadera vulnerabilidad de los jóvenes se encuentra asociada a distintas formas de perversión naturalizadas en contextos cotidianos como la familia y la escuela, en la que los jóvenes se encuentran sometidos a relaciones jerarquizadas y de servidumbre, anulando su mismidad e incluso sus derechos y seguridad vital. Actitudes como la obediencia, sumisión, respeto a la autoridad, son algunos de los valores compartidos por estas instituciones que favorecen la actitud poco crítica ante influencias sectarias.

Según Saraví (2009) en la perversión moral, el perverso intenta dominar, utilizar y envilecer al otro a través de la manipulación, utilizando para ello un lenguaje simpático, marcado por la seducción y el cinismo, aunque a veces puede mostrarse impetuoso y arrogante. De ahí que en las sectas las familias se presentan al captado como origen del mal, de la perversión y de contaminación de la interioridad. En consonancia, las voces de las familias de hijos que entran en sectas manifiestan principalmente el sentimiento de pérdida del ser querido.

Además, este momento evolutivo no escapa de la crisis que se planteaba en el primer apartado, es más, sus singularidades lo hacen un momento especialmente delicado (Jansà 2015). Podría decirse que el ser adolescente se encuentra en un periodo especial de búsqueda de sentido y en este cometido encuentra las mismas dificultades que se han abordado anteriormente, quizás incluso más agudamente, ya que han sido desarmados de su capacidad crítica por un sistema de educación permisivo y sobreprotector. Los adolescentes nacidos en una sociedad del espectáculo y el consumismo, están acostumbrados a huir de la profundidad y del esfuerzo, saltando de una cosa en otra, sin pararse en nada, dando lugar a lo que Esquirol (2012) denomina sociedad evasiva.

Nos encontramos ante el empobrecimiento de una generación construida en la abundancia, que ha propiciado el desanimo y aburrimiento mas que la capacidad emprendedora. De hecho, tal y como exponen Moral y Ovejero (2004) en momentos de desilusiones masivas, algunos jóvenes con miedo a la libertad, en terminología frommiana, se consuelan del desánimo ya sea con sobreactivaciones varias, a través de la conformidad automática o mediante la redefinición de identidades difusas.

Esta adolescencia social en desánimo, que llaman estos autores, es una auténtica mina para la captación sectaria, pues como ya describía Rodríguez (1994), para que pueda darse la captación deben coincidir cuatro condiciones, que en su convergencia dan lugar a lo que llama momento oportuno: 1 . Tener un perfil presectario de personalidad, 2. Estar atravesando un momento de crisis 
personal, que rebose las capacidades del individuo para soportar el estrés o la angustia, 3. ser contactado de un modo adecuado por un reclutador sectario, y 4. Que el mensaje propuesto encaje con las necesidades de la víctima.

Dejando a un lado el asunto del perfil presectario de personalidad, que parecer depender más de la singularidad de cada individuo, se puede asumir que los tres últimos puntos sí pueden conformar, en general, factores de riesgo durante la adolescencia y la primera juventud: es el periodo evolutivo más crítico en la construcción de uno mismo; en el que se trata de consolidar, no sin dificultades, la personalidad y la identidad, en una disputa por adaptarse al medio (muchas veces extremadamente complejo, dinámico y desalentador), en los que se buscan modelos y referencias (que no siempre son seguros), a la vez que se desarrollan pautas o estrategias de enfrentamiento con lo que se presenta como realidad opresiva y/o adversa. Es decir, «se experimenta con crudeza el dolor del proceso de crecer (fracasos, frustraciones, responsabilidades, miedos, estrés, etc.)»(Rodríguez, 1994, p. 70). La inmadurez propia y la desarmonía evolutiva que se mencionada anteriormente de esta etapa sumadas a la multiplicidad de conflictos vividos en un contexto (social, ideológico y emocional) inestable, inseguro y con pocas esperanzas o garantías de futuro, incrementa significativamente la vulnerabilidad frente a las trampas que se presentan como reductoras de ansiedad, entre ellas, la ofertas del universo sectario.

Con relación a los factores que hacen referencia al encuentro con el captador y a la conveniencia del mensaje que, a modo de cebo, se oferta desde estas organizaciones a los jóvenes, también se pueden encontrar amenazas específicas relacionadas con la adolescencia. El joven que se aventura naturalmente en la búsqueda de sí mismo y de su lugar en el mundo se enfrenta al riesgo de ser engañado por quienes le esperan y se han especializado en obtener beneficios de sus debilidades de este momento de trance. Como indica Bustamante Laos (2008), este momento de trance, «significa pensar simultáneamente en dos tránsitos: por un lado el tránsito adolescente y, por el otro, el tránsito cultural por el que nuestra sociedad pasa» (p. 5), momento que se caracteriza por «la dificultad de poner nombre y simbolizar la vertiginosa cantidad de experiencias que la posmodernidad nos pone por delante» (p. 5).

Para explicar el éxito de esta relación captador-oferta-captado, la metáfora resulta tristemente sencilla: es ofrecer promesas de agua al sediento. Como aseguran Moral y Ovejero (2004), «los adolescentes en su período de definición personal necesitan referencias y referentes, acciones simbólicas e iconos, valores y significados atribuidos, etc., que, en condiciones de inestabilidad, actúen como elementos que contribuyan a dar sentido a sus búsquedas». En un momento de debilidad, como proponen los autores, el señuelo de las 
promesas sectarias puede presentarse como una respuesta brillante, cargada de sentido, autenticidad, originalidad, pertenencia, transcendencia, madurez y éxito personal. Como bien explica Jiménez Tallón (1997), la existencia angustiosa, la confusión y la inseguridad (que pueden caracterizar con demasiada frecuencia esta etapa) hace al joven más inerme y "por lo tanto, más susceptible de dejarse llevar por seductoras soluciones a esos problemas y ambientes ideales prometidos donde todo eso dejará de tener sentido» (p. 119).

Estas organizaciones se sirven en muchas ocasiones de estrategias diseñadas con gran perfeccionamiento y de técnicas especializadas para la persuasión, la captación y el proselitismo, desarrolladas con una inteligencia precisa y perversa, extraordinariamente bien enfocada a explotar estas debilidades; generalmente activando emociones de un nivel tal elevado que «como dirían los clásicos griegos dirían, confunden a la razón» (Cuevas \& Canto, 2006).

En algunos casos, también en esta etapa se encuentran debilidades derivadas de la búsqueda activa de carácter religioso-espiritual, que acostumbra a estar caracterizada por aspiraciones de perfección y transcendencia, la preponderancia del pensamiento mágico, la susceptibilidad o atracción por los estados alterados de conciencia y la apetencia por experimentar estos estados (Rodríguez, 1994). Estas aspiraciones están muy relacionadas con las fantasías juveniles de omnipotencia, que en situaciones de crisis personal, adquieren «valor de refugio liberador y protector» suponiendo «una puerta a mensajes salvíficos que caracterizan a las sectas de índole religiosa» (p. 74). Es un momento también especialmente sensible para establecer una relación de fijación u obsesión con los líderes carismáticos que suelen conducir este tipo de organizaciones.

\subsection{Proceso de captación}

Como se ha puesto de manifiesto, existen factores de vulnerabilidad que favorecen la captación de los sujetos por la secta (soledad, baja autoestima, inestabilidad emocional, etc.), pero también existen métodos que facilitan la conversión y afiliación, y estos atraviesan distintas fases. Para Benoit y Cancrini (2014) todo comienza con la captación, donde hay miembros de la secta entrenados para buscar nuevos devotos y para ponderar las perspectivas de éxito con las que cuentan a partir de la observación y de conversaciones aparentemente triviales. La etapa de la persuasión es fundamental para estrechar el vínculo de camaradería con el nuevo devoto. Se trata de ganarse la confianza del otro, lo colman de atenciones, y le ofrecen la comunidad religiosa como el espacio que llena de sentido su existencia y da luz a sus problemas. 
Se inicia la conversión con la asistencia a cursos de formación donde probablemente el nuevo devoto se muestre perplejo ante algunas ideas, que rápidamente serán desviadas. Se amplía el número de miembros de confianza del devoto entre los sectarios, así como el número de encuentros, en los que casualmente se van introduciendo poco a poco las ideas fundamentales de la secta, empleando términos cordiales pero firmes. El sujeto se encuentra expuesto a múltiples influencias y apenas presta atención a su contenido. Una vez que el aspirante se muestra receptivo se produce el adoctrinamiento donde se intenta llevar a cabo una profunda transformación ideológica, y con el tiempo el iniciado hace suyo el estilo de vida y la visión del mundo de la secta.

Llegado a este punto, la secta castiga fuertemente cualquier desobediencia. La cantidad y diversidad de abusos que los devotos sufren en las sectas solo son comparables con las posibilidades que abre la creatividad. En cualquier caso con un leve acercamiento a las lecturas que nos brindan los medios de comunicación y la literatura existente sobre la temática podemos hacernos una imagen del horror que pueden llegar a vivir (abusos sexuales, castigos físicos, estafas para autofinanciar la secta, asesinar, etc.). Se trata de una anulación total del ser, quien se encuentra sometido a la voluntad de un líder quien poseedor de un océano de conocimiento filosófico-religioso y dueño de una personalidad carismática como para encantar a jóvenes desencantados.

Para Fulco (2011) los devotos de una secta son denominados como los pasajeros de una pesadilla, que comienza con el alejamiento de una comunidad (familia-escuela, amigos) para adentrarse en otra, la sectaria, que bajo palabras como amor, lealtad, fidelidad introducen al devoto en un proceso de construcción interior cuyas exigencias crecen exponencialmente, especialmente cuando este se ha visto desprovisto de cualquier vinculo ajeno a la comunidad. De ahí la dificultad de salir de estas prisiones. Por eso el sentimiento de pertenencia desempeńa un papel crucial en la secta, quien recurre en ocasiones a símbolos y talismanes para favorecer esa identificación del devoto con la comunidad. Así, se reconocería como secta a «aquella organización religiosa que presentara las características de voluntariedad, exclusivismo y exigencia de méritos hacia sus adeptos, a los que serviría como vía de identidad y en los cuales estimularía una conciencia de pertenencia a un cierto tipo de élite» (García-Jorba, 1992, p. 15).

\section{4. ¿CÓMO PREVENIR La CAPTACIÓN? UNA RESPONSABILIDAD EDUCATIVA}

Como bien indica el epígrafe de este apartado, la prevención de la captación es una responsabilidad educativa, también referida a la escuela, tanto por ser un agente fundamental en socialización secundaria, como por ser un 
acompañante esencial en el desarrollo del alumno y uno de los garantes principales, como institución, de sus derechos fundamentales.

Fournier y Picard (2004, p. 224) aseveran que: «La primera misión de los grupos sociales en términos educativos es la protección", que, evidentemente, hacemos extensible también a los adolescentes y jóvenes que acogen las instituciones educativas y que no debe limitarse solamente a la defensa y el cuidado físico y psicológico, esto debe de ser el mínimo, sino que debe aspirar a formar a alumnos felices, críticos, autónomos y, sobre todo, libres. Esta es sin duda la primera clave y la primera herramienta de defensa que la escuela puede regalar a sus alumnos frente a estas manipulaciones: educar para la libertad.

Como exhortaba Rodríguez (1994) hace ya más de dos décadas, «ante la práctica habitual del sistema educativo actual que es, en buena medida, una fábrica de personales neuróticas [...] hay que introducir buenas dosis de imaginación, creatividad, libertad, relativismo y sentido común» (p. 115). En cierta medida, y como se apuntaba anteriormente, actitudes como la obediencia, sumisión, respeto a la autoridad, son algunos valores compartidos y apreciados generalmente por estas instituciones conforman en este caso una debilidad.

Para brindar una educación que proteja y enseñe a proteger hay que respetar primeramente la individualidad del niño y desarrollar los valores que promuevan la visión crítica, la libertad y la autonomía, «en resumen, evitar cualquier forma de apropiación» (Fournier \& Picard, 2004, p. 224). Es decir, se precisa de un modelo que potencie el pensamiento racional y crítico, que fortalezca a su vez la asertividad y los mecanismos saludables para la toma consciente de decisiones. Evidentemente, todo este valioso bagaje no solo es útil para la defensa contra las trampas del universo sectario, sino que conforman un rico andamiaje para la el desarrollo integral del individuo, que lo protege, de forma transversal, de caer en muchos otras complicaciones que tristemente están a la orden del día y que comprometen la vida, como la violencia de género, el fanatismo religioso, los abusos sexuales, las bandas criminales, etc. En este sentido, hablamos de una doble ventaja: cuanto más solida y saludable es la construcción personal del individuo, mejor y más feliz es su adaptación y su desarrollo en su medio (mejor calidad de vida) y más seguro y protegido se encuentra, empezando desde su propia protección interna, frente a estos peligros.

La escuela debe ofrecerse como un agente de cuidado en distintas dimensiones: en primer lugar ofreciendo una formación que permita la construcción solida del individuo y su autodefensa. Además, como garante de los derechos fundamentales de sus alumnos, debe mantener una actitud de prevención, vigilancia y alerta, dar la voz de alarma si detecta situaciones de peligro o abuso y dotarse convenientemente de recursos, herramientas, planes y protocolos 
que le permitan proteger a sus alumnos/as de esta y otras amenazas. En este mismo sentido, debería erigirse como una agente fundamental de autoridad y confianza, especialmente representado en las figura del tutor, el cuál debería ser un referente fundamental al que pedir auxilio. No debe perderse de vista que «la misión educativa consiste asimismo en arropar afectivamente al niño» (Fournier \& Picard, 2004, p. 224).

Por el contrario, la terquedad escolar, declarada con descaro en el desarrollo curricular, que prima los contenidos declarativos y se enfoca perversamente en la obtención de resultados puramente académicos (donde el alumno parece ser un medio y no en un fin en sí mismo), se presenta como uno de los defectos en el enfoque que imposibilita el desarrollo de esta atención: la escuela no está para cuidar sino para enseńar. Debe entender que el cuidado y el reconocimiento es el pilar fundamental de cualquier enseńanza-aprendizaje que merezca verdaderamente la pena.

Somos conscientes de la precariedad de la respuestas educativas, no tanto porque estas se vean superadas por la realidad como reconoce Bellera (2013, p. 166) «Por mucho que intentemos programarla, por muy bien que nos organicemos, siempre surge un momento en el que parece que las cosas no responden a las expectativas y los resultados nos defraudan", sino porque se encuentran alejadas de la misma, tal y como expone Ortega (2010, p. 14) «no hay educación si no hay pregunta; no hay educación si no hay respuesta a una persona concreta y singular. Mientras las conductas justas, tolerantes y solidarias no sean cuestiones-preguntas que afectan a un sujeto, es decir, mientras el sujeto no se sienta interpelado, preguntado, no debemos esperar respuesta alguna sobre esas conductas». La respuesta educativa ha de nacer de la condición histórica del otro, solo así el otro deja de ser un desconocido para ser reconocido.

La escuela no puede resumirse, como duramente critica Nussbaum (2010, citada en Acosta, 2013), en una organización sin alma, ocupada en la asimilación obsesiva y acrítica de conocimientos rentables, desde un sentido casi exclusivamente industrial e utilitarista, abandonando el cuidado por el desarrollo integral del ser, que, volviendo al tema que nos ocupa, resulta esencial para la prevención.

Otro de los ejes de intervención esenciales es romper con la apatía que rodea a los adolescentes, especialmente cuando estos han vivido contextos de sobreestimulación y no hay nada que les sorprenda, que les motive. En ocasiones la dispersión y la apatía se muestran como un estado deseable «cuando tenemos alumnos sobreestimulados, pues un exceso de estimulación lleva a una falta de deseos por aquel peligro de avanzarse a lo que puede preguntarse o desear al niño/a o joven anticipándose a que surja en él su estímulo» (Peréz, Gargallo, 
Burguet \& López, 2015, p. 202). Los deseos de los niños suelen ser cumplidos antes de ser enunciados.

Nos encontramos ante una generación colmada por naturaleza, no acostumbrada al esfuerzo, a la necesidad, al sacrificio. En este sentido, la supremacía del tener ha mermado las posibilidades del ser, quien ha entrado en una apatía constante por la vida. No son capaces a formularse pasiones o retos en la vida, y esperan que estos les vengan dados. Las familias y las escuelas tienen una función importante en este sentido, y es despertar en el otro la pasión por la vida, enseńando que esto incluye en ocasiones enfrentarse a la frustración, la ambigüedad, la confusión o el desencanto, asumiendo que le son intrínsecas, especialmente en el afrontamiento de la vida adulta, pero que no le restan valor.

Es esencial también para esto nutrir el sentimiento de utilidad y pertenencia, como se ha apuntado anteriormente. Esto debe darse en una estrecha asistencia entre la familia y la escuela (como agentes fundamentales de socialización) y con especial esmero en fomentar la integración de los alumnos que pueden encontrarse en riesgo de exclusión. Resulta fundamental reforzar la autoestima y la seguridad personal, que están íntimamente ligados con la posición que ocupamos (o que creemos ocupar) y el grado de adaptación al propio contexto social como lugar de desarrollo. Como dinámica socializadora por excelencia en esta etapa, la escuela puede promover "patrones de conducta capaces de orientar sus actuaciones presentes y futuras hacia comportamientos más sanos» que permita a sus alumno «mantener de la mejor manera posible una relación homeostática, racional, adulta y ecológica con uno mismo y con el entorno donde vive» (Rodríguez, 2004, p. 114).

Con relación al desarrollo en el contexto social del aula, algunos estudios demuestran que los adolescentes que disfrutan compartiendo actividades que potencian las relaciones sociales o que comparten de forma cooperativa en actividades de trabajo o tiempo libre presentan menos síntomas psicopatológicos como ansiedad, depresión, fobias o síntomas obsesivo-compulsivos (Garaigordobil, 2006; citado en Giménez, Vázquez \& Hervás, 2010). Por tanto, fomentar desde el aula este tipo de participación, no solo disminuye los riesgos con respecto al fenómeno sectario, sino que se presenta una gran variedad de ventajas tanto para el aprendizaje como para el desarrollo saludable que no se deberían desaprovechar.

\section{ConClusión}

En conclusión, se puede entender que para afrontar el fenómeno sectario, la estrategia clave es la prevención. Como explica Rodriguez-Carballeira (2001) 
"para afrontar la problemática sectaria, más que tratar de erradicar determinados grupos, hay que centrarse en una prevención global y en un tratamiento individualizado de cada caso» (p. 129). En esta intención la educación juega un papel fundamental, que su asumiendo su responsabilidad de formar personas libres y autónomas, puede vigorizar el espíritu crítico e independiente que proteja al alumno frente a estos riesgos. Esto incluye además la cristalización de redes de apoyo y de contextos de protección que permitan una socialización sana y el desarrollo integral de cada alumno.

También se debe informar activamente a los jóvenes y adolescentes de los riesgos a los que se exponen, como medida de prevención frente a posibles situaciones futuras de persuasión coercitiva. Se debe enseñar a identificar que «es la persuasión coercitiva, detectar diferentes situaciones de engańo y manipulación encubiertas, grupos con historias en la aplicación de estas estrategias coercitivas» (Cuevas \& Canto, 2006, p. 32). Para esto se debe ayudar a desarrollar una actitud madura, crítica y consciente frente a lo religioso y a las propias necesidades de sentido y transcendencia.

Esta formación, que por supuesto no debe ser de por sí antirreligiosa, sí debe explicar que si bien las religiones puede completar, favorecer o ayudar a las personas y las sociedades (la discusión sobre esto merece un aparte), ciertas formas pueden presentar riesgos que conviene saber identificar: la clave está en aprender a distinguir entre las aspiraciones espirituales saludables y legítimas de los yugos que destruyen y esclavizan, delimitando una serie de líneas rojas que bajo ningún concepto se deben transgredir, y que se fundamentan todas ellas en la conservación de la dignidad y, sobre todo, de la libertad. Como propone Rodríguez (1994), dentro del marco de la educación para la salud integral, (y no solo dentro de ese marco, si no de la propia educación para la vida o la educación para la libertad) el peligro que supone el sectarismo debería ser un punto de ocupación, reflexión y análisis, que además debería comprenderse como un peligro específico en cualquier situación de crisis (ya sea personal o social) como la que se ha venido arguyendo.

Para finalizar, la escuela no puede ser un ficticio islote de paz, una burbuja de cristal alejada de la realidad. Vivimos en un mundo contradictorio en donde convergen la solidaridad y la paz junto a la destrucción y la violencia, la generosidad y amistad junto a la envidia y el egoísmo. La vida misma es un devenir entre lo bueno y lo malo, lo correcto e incorrecto. De ahí que la educación ha de atender a las dos caras de esta moneda por desagradable que resulte. Educar en el desconocimiento y la negación de la mezquindad de algunos seres humanos es lanzar al mundo una generación desarmada de las herramientas (valores) que le permitan hacerle frente. 


\section{REFERENCIAS BIBLIOGRÁFICAS}

Acosta, J. (2013). Educar para la felicidad. Instituciones educativas vivas. Boyacá: Fundación Universitaria Juan de Castellanos.

Alapont, P. (2005). Barrotes dorados. Alzira: Algar.

Biglan, A., Brennan, P. A., Foster, S. L. \& Holder, H. D (2004). Helping Adolescents at Risk: Prevention of Multiple Problem Behaviors. Nueva York: The Guilford Press.

Bauman, Z. (2005). Modernidad líquida. Buenos Aires, Argentina: Fondo de Cultura Económica.

Bauman, Z. (2012). Esto no es un diario. Barcelona: Planeta.

Bellera, J. (2013). Nuevos escenarios para el aprendizaje cambiando las reglas del juego educativo. Tendencias Pedagógicas, 22, 165-176.

Benoit, S. y Cancrini, S. R. (2014). Sectas y sectarios: Psicopatología de un fenómeno esclavizante. Madrid: Ediciones De Buena Tinta.

Bustamante, A.I. (2008). Adolescencia y filosofía. Padres y Maestros, 319, 5-8.

Canteras, A. (2004). Sociología del fenómeno sectario: elementos para su interpretación. Eguzkilore, 18, 173-193.

Cuevas, J. M. \& Canto, J. (2006). Sectas. Cómo funcionan, cómo son sus líderes, efectos destructivos y cómo combatirlas. Málaga: Aljibe.

Dubet, F. (2006). El declive de la institución. Barcelona: Gedisa.

Elzo, J. (2004). La familia entre la añoranza estéril y las incertidumbres de futuro. En AA.VV. La familia en la sociedad del siglo XXI. Madrid: FAD.

Esquirol, J. M. (2012). Finitud y duración. Convivium: Revista de Filosofía, 25, 209-220.

Fierro, A. (1979). Sobre la religión: descripción y teoría. Madrid: Taurus.

Fournier, A. \& Picard, C. (2004). La falsa espiritualidad y la manipulación de los individuos. Sectas, democracia y mundialización. Barcelona: Paidós Ibérica.

Freire, P. (2001). Pedagogía de la indignación. Madrid: Morata.

Fulco, M. (2011). Pasajeros de una pesadilla. El Guardian. Recuperado de http:// victimasectas.com/MaestroMehir/ElGuardian.pdf

Gabilondo, A. (2001). La posmodernidad en el agua y la posmodernidad en el alma. Daimon: Revista de Filosofia, 22, 89-104.

García, E. (2008). Posmodernidad y religión. «Nueva Era». Teoría y Praxis, 12, 70-86.

García-Jorba, J. M. (1992). Las rejas de la fe: análisis en torno a la construcción de la imagen social de las sectas. Arxiu d»Etnografia de Catalunya, 9, 12-36. 
Giménez, M., Vázquez, C. \& Hervás, G. (2010). El análisis de las fortalezas psicológicas en la adolescencia: Más allá de los modelos de vulnerabilidad. Psychology, Society, \& Education, 2(2), 83-100.

Jansá, J. M. (2015). School program for adolescents to prevent cult manipulation. Psychosocial determinants. Recuperado de http://fecris.org/wp-content/ uploads/2015/05/english-Jansa.pdf

Jiménez-Tallón, M. A. (1997). Factores de predisposición y prevención del fenómeno sectario. Carthaginensia, XIII(23), 115-128.

Lahire, B. (2007). Infancia y adolescencia: de los tiempos de socialización sometidos a constricciones múltiples. Revista de Antropología Social, 16, 21-38.

Moral, M. \& Ovejero, A. (2004). Jóvenes, globalización y posmodernidad: crisis de la adolescencia social en una adolescencia social en crisis. Recuperado de http://www.papelesdelpsicologo.es/vernumero.asp?ID $=1142$

Ortega, P. (2010). Educar es responder a la pregunta del otro. Edetania: estudios y propuestas socio-educativas, 37, 13-31.

Pérez, C., Gargallo, B., Burguet, M. \& López, I. (2015). La educación inclusiva y solidaridad ciudadana. En J. L. González-Geraldo (coord.), Educación, desarrollo y cohesión social (pp. 181-218). Cuenca: Ediciones de la Universidad de Castilla La Mancha.

Rodríguez, P. (1994). Tu hijo y las sectas. Guía de prevención y tratamiento para padres, educadores y afectados. Madrid: Ediciones Temas de Hoy.

Rodríguez-Carballeira, A. (2001). Sectas coercitivas y juventud. Estudios de Juventud, 53, 117-119.

Saraví, G. (2009). Transiciones vulnerables. México, D.F.: Ciesas. 